Goldschmidt 2021 Abstract

https://doi.org/10.7185/gold2021.6364

\section{Contribution of the world's main dust source regions to the global cycle of desert dust}

\author{
JASPER F. KOK ${ }^{1}$, ADEYEMI A. ADEBIYI ${ }^{2}$, SAMUEL \\ ALBANI $^{3}$, YVES BALKANSKI ${ }^{4}$, RAMIRO CHECA- \\ GARCIA $^{5}$, MIAN CHIN ${ }^{6}$, PETER COLARCO ${ }^{6}$, DOUGLAS \\ HAMILTON $^{7}$, YUE HUANG ${ }^{2}$, AKINORI ITO ${ }^{8}$, MARTINA \\ KLOSE $^{9}$, LONGLEI LI ${ }^{7}$, NATALIE MAHOWALD ${ }^{7}$, RON L. \\ MILLER $^{10}$, VINCENZO OBISO ${ }^{11}$, CARLOS PEREZ \\ GARCIA-PANDO $^{12}$, ADRIANA ROCHA-LIMA ${ }^{13}$ AND \\ JESSICA WAN $^{7}$ \\ ${ }^{1}$ University of California, Los Angeles \\ ${ }^{2}$ University of California \\ ${ }^{3}$ University of Milano-Bicocca \\ ${ }^{4}$ CEA-CNRS-UVSQ, IPSL \\ ${ }^{5}$ CEA-CNRS-UVSQ-UPSaclay \\ ${ }^{6}$ NASA GSFC \\ ${ }^{7}$ Cornell University \\ ${ }^{8}$ JAMSTEC \\ ${ }^{9}$ Barcelona Supercomputing Center (BSC) \\ ${ }^{10}$ NASA Goddard Institute for Space Studies (GISS) \\ ${ }^{11}$ NASA Goddard Institute for Space Studies \\ ${ }^{12}$ ICREA, Catalan Institution for Research and Advanced \\ Studies \\ ${ }^{13} \mathrm{UMBC}$ \\ Presenting Author: jfkok@ucla.edu
}

Even though desert dust is the most abundant aerosol by mass in Earth's atmosphere, the relative contributions of the world's major dust source regions to the global dust cycle remain poorly constrained. This problem hinders accounting for the potentially large impact of regional differences in dust properties on clouds, the Earth's energy balance, and terrestrial and marine biogeochemical cycles. Here, we constrain the contribution of each of the world's main dust source regions to the global dust cycle. We use an analytical framework that integrates an ensemble of global model simulations with observationally informed constraints on the dust size distribution, extinction efficiency, and regional dust aerosol optical depth. We obtain a data set that constrains the relative contribution of each of nine major source regions to size-resolved dust emission, atmospheric loading, optical depth, concentration, and deposition flux. We find that the 22-29 $\mathrm{Tg}$ (one standard error range) global loading of dust with geometric diameter up to $20 \mathrm{um}$ is partitioned as follows: North African source regions contribute $~ 50 \%$ (11-15 $\mathrm{Tg}$ ), Asian source regions contribute $\sim 40 \%$ (8-13 Tg), and North American and Southern Hemisphere regions contribute $\sim 10 \%$ (1.8-3.2 Tg). Current models might on average be overestimating the contribution of North African sources to atmospheric dust loading at $\sim 65 \%$, while underestimating the contribution of Asian dust at $\sim 30 \%$. Our results further show that each source region's dust loading peaks in local spring and summer, which is partially driven by increased dust lifetime in those seasons. We also quantify the dust deposition flux to the Amazon rainforest to be $\sim 10 \mathrm{Tg} /$ year, which is a factor of 2-3 less than inferred from satellite data by previous work that likely overestimated dust deposition by underestimating the dust mass extinction efficiency. The data obtained in this paper can be used to obtain improved constraints on dust impacts on clouds, climate, biogeochemical cycles, and other parts of the Earth system.
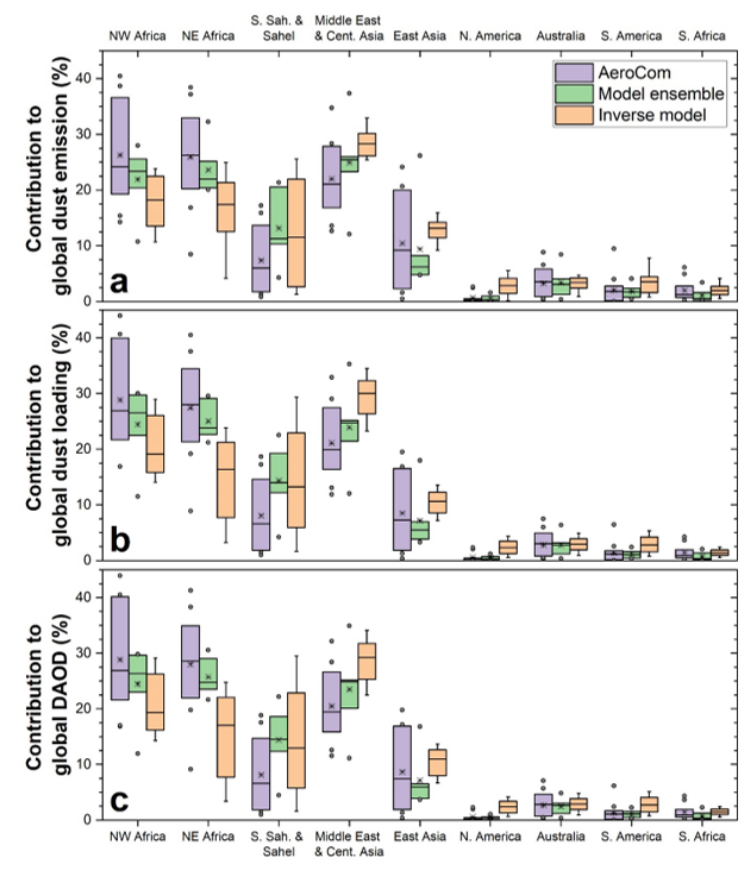

Fractional contribution of each source region to the global dust cycle. Shown are the fractional contributions to the annual

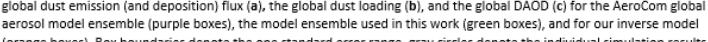
(orange boxes). Box boundaries denote the one standard error range, gray circles denote the individual simulation results outside of this range, vhiskers denote the $95 \%$ confi
the median result, and stars denote the mean result 